\title{
Ensaios estáticos e cinemáticos de receptores de GPS
}

\author{
Thiago M. Machado ${ }^{1} \&$ José P. Molin ${ }^{1}$
}

\section{RESU M O}

O s sistemas de navegação global por satélites, em especial o GPS, mais completo e conhecido, tem multiplicado suas aplicações no meio agrícola. O desempenho de receptores, no entanto, não é devidamente conhecido entre os usuários; assim, este trabalho visou avaliar receptores com distintas configurações e o uso de correções diferenciais por meio de ensaios estáticos e cinemáticos; no primeiro caso foram avaliados, concomitantemente, oito receptores ativando ou não as correções diferenciais WAAS e EGNOS, além de sinais privados específicos para alguns desses receptores; também se testaram intensidades de filtragem disponíveis em alguns dos receptores. No ensaio cinemático utilizaram-se dois receptores de navegação fixados sobre a cabine de um trator, tendo como referência um receptor GPS RTK. Na primeira avaliação os resultados mostraram que as correções W AAS e EG NO S não adicionam qualidade ao posicionamento na região de Piracicaba, SP. As correções diferencias privadas via satélite demonstraram ser mais acuradas que os demais sistemas avaliados. 0 ensaio sob condição cinemática, com GPS RTK de referência, permitiu o cálculo de erros no sentido perpendicular ao percurso, indicando ser de fácil execução.

Palavras-chave: agricultura de precisão, correções diferenciais, RTK

\section{Static and cinematic tests of GPS receivers}

\begin{abstract}
The global navigation satellite systems, especially the GPS, well known and totally implemented, have been intensively used in agriculture. The performance of receivers, however, is not properly disseminated among the users, so the aim of this work is to evaluate receivers with distinct configurations and the use of differential corrections through static and cinematic tests. In the first case eight receivers were tested activating or not the differential corrections WAAS and EG NOS, besides specific augmentation signals for some of the receivers and filtering intensities available for some of the receivers. In the cinematic condition two navigation receivers were mounted on the top of a tractor cab and tested using a G PS RTK receiver as reference. In the first evaluation the results showed that W AAS and EG NOS corrections do not add quality to the positioning in the Piracicaba, SP region. The private differential corrections by satellite were more accurate than the other systems tested. The test under cinematic condition, using a GPS RTK receiver as reference allowed the easy computation of the errors in the perpendicular of travel direction.
\end{abstract}

Key words: precision agriculture, differential corrections, RTK 


\section{INTRODUÇÃO}

Os Sistemas de Navegação Global por Satélites (SNGS), ou "Global Navigation Satellite Systems" (GNSS) foram desenvolvidos, inicialmente, para fins bélicos e resultaram em métodos de localização que estão influenciando e revolucionando inúmeras atividades e setores da economia, dentre eles a agricultura. Um dos principais componentes do GNSS é o "Global Positioning System" (GPS), desenvolvido pelos Estados Unidos e que se encontra em plena operação; outroé o "Global'naya Navigatsionnay Sputnikovaya Sistema" (GLONASS), da Rússia; há ainda, o sistema Galileo, projetado pela "European Space Agency" (ESA), da União Européia, e o sistema chinês, denominado Compass, ambos em construção (Wolfgang \& Baumann, 2000).

Em função da sua disponibilidade, o GPS tem sido o mais utilizado e passou a representar uma ferramenta com contribuições inovadoras na agricultura. Nesse caso, é utilizado, comumente, em atividades que demandam posicionamento com distintos níveis de acurácia para diferentes aplicações associadas às investigações georreferenciadas e intervenções localizadas, as quais visam ao máximo aproveitamento dos recursos e insumos e minimização de efeitos indesejáveis ao ambiente dando sustentação às técnicas conhecidas como Agricultura de Precisão (Motomiya et al., 2009). O GPS também passou a ser intensamente utilizado como recurso de orientação e guia para veículos agrícolas (Bergtold et al., 2009; Silva et al., 2011), aviões agrícolas (Smith \& Thomson, 2005), como sensor de velocidade em veículos agrícolas (Molin et al., 2005), no monitoramento de transporte e logística da produção agrícola (Devlin et al., 2007), na automação como em robôs agrícolas (Nørremark et al., 2008), dentre outros.

A carência de informações técnicas sobre o desempenho de receptores de GNSS tem gerado dúvidas entre os usuários, especialmente sobre qual categoria de receptor utilizar para aplicações específicas. Observa-se a ausência de metodologias com base em princípios estatísticos robustos para avaliação da qualidade dos resultados de posicionamento para diferentes categorias de receptores e em diferentes condições de trabalho e aplicações, especialmente naquelas que contemplam condições cinemáticas, comuns na agricultura.

A utilização de receptores de navegação autônomos tem sido intensificada e muitos os utilizam com o sinal "Wide Area Augmentation System" (WAAS) ativado, esperando tem melhor acerto no posicionamento, porém sequer se sabe se este sinal que estão recebendo é WAAS ou é do "European Geostationary Navigation Overlay Service" (EGNOS), pois ambos operam na mesma frequência. Esses sistemas de correção com sinais abertos, portanto sem custo para o usuário, transmitidos via satélites de comunicação, tem ação sobre territórios definidos; também existem sistemas semelhantes porém privados e com custo para o usuário. No entanto, em locais para os quais tais sinais são destinados, sua efetividade é comprovada. Em ensaios estáticos e cinemáticos com diversos receptores, na Flórida, EUA, Min et al. (2008) comprovaram a efetividade tanto do sinal WAAS como do sinal de correção diferencial da Guarda Costeira ("Coast Guard Beacon”) na redução do erro de posicionamento.
Utilizando um sinal aberto (WAAS) e um privado (OmniSTAR) em ensaio estático com vários receptores de GPS, Sullivan et al. (2001) observaram que as correções funcionam bem e podem ser usadas em AP. Cappelli et al. (2006) ensaiaram receptores $\mathrm{L} 1, \mathrm{C} / \mathrm{A}$ de uso agrícola e receptores código $\mathrm{C} / \mathrm{A}$ usados para navegação, em modo estático, utilizando correções diferencias em tempo real e observaram que há diferença de acurácia e precisão entre os receptores e o uso da correção diferencial permitiu um aumento significativo em ambas.

Os fabricantes de receptores de GPS utilizados em AP, quando muito, disponibilizam relatórios do desempenho de seus receptores no modo estático, porém os desempenhos obtidos em ensaios estáticos nem sempre são indicativo de desempenho cinemático (Stombaugh et al., 2002).

Autores têm avaliado o desempenho de receptores de GNSS com as antenas montadas sobre veículos utilizando, via de regra, um receptor de GPS RTK como referência para o cálculo dos erros (Ehsani et al., 2003). Nessas condições, Molin \& Carrera (2006) avaliaram quatro receptores com três velocidades de deslocamento e observaram que velocidades menores resultaram em erro maior, quando os receptores estavam configurados para coletar dados com base em intervalos de tempo. Chosa et al. (2006) desenvolveram uma plataforma circular de ensaio cinemático para receptores de GPS RTK, mensurando a variação de velocidade e o erro do ângulo de trajetória, tendo como referência um detector magnético de pulsos. Observa-se que a mensuração de erro de posicionamento em modo cinemático é mais difícil que em modo estático, uma vez que as variáveis que afetam o desempenho cinemático dos receptores GPS são de mais difícil controle (Buick, 2002).

Considera-se que existe a necessidade premente de se oferecer informação confiável aos usuários de GNSS para a correta seleção entre as soluções de mercado. Da mesma forma, observa-se que não há informação suficiente entre os usuários a respeito dos sinais diferenciais públicos; sendo assim, o presente trabalho tem o objetivo de discorrer sobre metodologias para ensaios estáticos e cinemáticos de receptores de GNSS, avaliando o desempenho de receptores que utilizam o sistema GPS em ambiente agrícola. Para tanto, numa primeira etapa o trabalho aborda a avaliação de configurações, sintonizações de correções diferenciais e mensuração da variação dos erros em ensaios estáticos e, em uma segunda etapa, aborda o cálculo dos erros em receptores de navegação em modo cinemático, tendo como referência um receptor RTK.

\section{Material DE MÉTODOS}

Na primeira etapa, o local escolhido para realização do ensaio foi uma torre livre de impedimentos físicos, localizada no Departamento de Engenharia de Biossistemas da Escola Superior de Agricultura "Luiz de Queiroz", ESALQ/USP, em Piracicaba, SP (coordenadas $22^{\circ} 42^{\prime} 41^{\prime \prime} \mathrm{S}$ e $47^{\circ} 37^{\prime} 50^{\prime \prime} \mathrm{W}$ ). Para obtenção das posições e cálculo dos erros uma estrutura metálica foi construída em formato de cruz, afixada na laje de concreto, sobre a referida torre, com o total de nove marcos 
distanciados 0,50 m um do outro (Figura 1). A estrutura foi georreferenciada por dois receptores L1/L2 Hiper GGD Topcon ${ }^{\circledR}$ geodésicos, com acurácia de $0,003 \mathrm{~m}+1 \mathrm{ppm}$, coletando dados com máscara de elevação de $15^{\circ}$, durante 1:30 h, com intervalo amostral de $15 \mathrm{~s}$ e pós-processados.

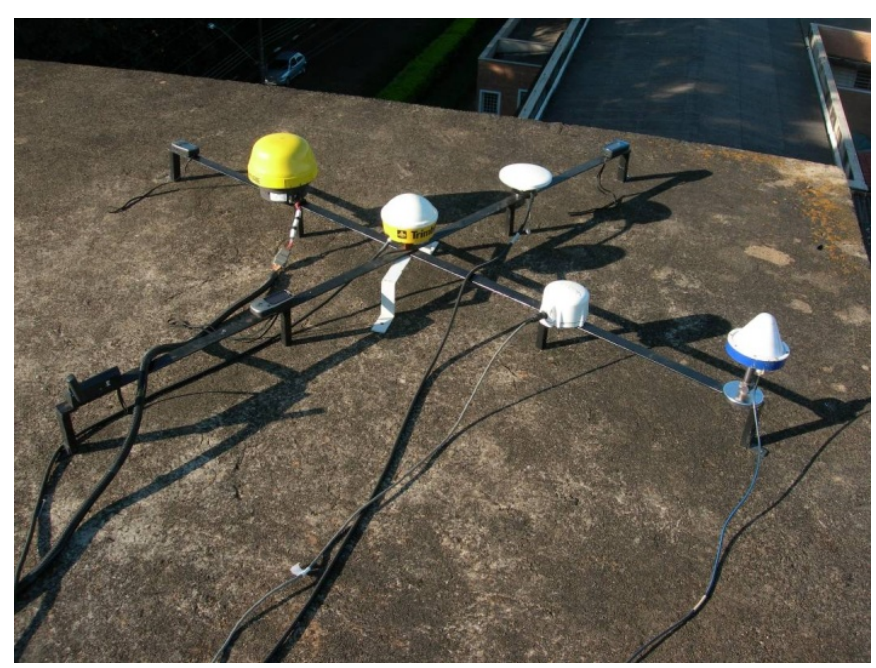

Figura 1. Receptores utilizados no ensaio dispostossobre a estrutura em cruz acima de uma torre

Obtiveram-se os valores de acurácia a partir das Eqs. de 1 a 6 (Buick, 2002; Ehsani et al., 2003; Stombaugh et al., 2005). O erro médio $(\mathrm{N}-\mathrm{E})$, ou média dos erros nas direções norte - sul e leste - oeste, é:

$$
\begin{array}{ll}
\mathrm{EE}=\mathrm{Xi}-\mathrm{Xr} & \mathrm{EN}=\mathrm{Yi}-\mathrm{Yr} \\
\mathrm{EME}=\overline{\mid \mathrm{EE}} \mid & \mathrm{EMN}=|\overline{\mathrm{EN}}|
\end{array}
$$

em que:

$\mathrm{EE}$ - erro na coordenada leste, $\mathrm{m}$

$\mathrm{EN}$ - erro na coordenada norte, $\mathrm{m}$

$X_{i}$ - valores das coordenadas leste, $m$

$\mathrm{X}_{\mathrm{r}}$ - coordenada real leste, $\mathrm{m}$

$\mathrm{Y}_{\mathrm{i}}^{\mathrm{r}}$ - valores das coordenadas norte, $\mathrm{m}$

$\mathrm{Y}_{\mathrm{r}}$ - coordenada real norte, $\mathrm{m}$

EME - erro médio na coordenada leste, $\mathrm{m}$

$\mathrm{EE}$ - média dos erros leste, $\mathrm{m}$

EMN - erro médio na coordenada norte, $m$

EN - média dos erros norte, $m$

O erro de posição - EP, é:

$$
\mathrm{EP}=\sqrt{\mathrm{EME}^{2}+\mathrm{EMN}^{2}}
$$

O desvio padrão ( $1 \sigma$ e $2 \sigma$ ) indica que 68 e $95 \%$ de todos os erros ocorreram dentro dos limites de $\pm 1 \mathrm{~s}$ e $\pm 2 \mathrm{~s}$, respectivamente, representando a precisão, pois usa a diferença de erro de posição e a média do erro de posição e resulta na indicação de espalhamento médio das coordenadas obtidas ao longo do período de coleta, ou seja:

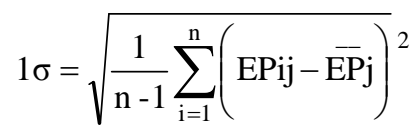

A raiz quadrada média do erro (RMS) indica a acurácia, haja vista que não utiliza a média, resultando no erro absoluto em relação à referência, representando 68\% de uma distribuição.

$$
\mathrm{RMS}=\sqrt{\frac{\sum_{\mathrm{i}=1}^{\mathrm{n}} \mathrm{EP}^{2}}{\mathrm{n}}}
$$

O erro circular provável (CEP) indica um limite que contém $50 \%$ de todos os erros em uma distribuição circular.

$$
\mathrm{CEP}=1,18 \sqrt{\sigma \mathrm{E}^{2}+\sigma \mathrm{N}^{2}}
$$

$\mathrm{oE}$ - desvio padrão na coordenada $\mathrm{E}$

oN - desvio padrão na coordenada $\mathrm{N}$

Os dados experimentais foram coletados em coordenadas geográficas (latitude e longitude) e transformados para coordenadas planas UTM (Universal Transversa de Mercator) utilizando-se o datum WGS-84. Para o cálculo dos erros das altitudes geométricas utilizou-se, como referência, a altitude estabelecida pelo receptor L1/L2 geodésico. Em cada um dos nove pontos se tem as coordenadas geográficas e a altura. Os erros negativos para a altitude se referem a valores abaixo da altura de referência e erros positivos são superiores à altura de referência.

Nos ensaios se utilizou receptores L1 código C/A comumente empregados em atividades agrícolas: Trimble AG132 (AG132), versão do firmware 3.00, 12 canais e frequência de atualização de $1 \mathrm{~Hz}$; SatLoc SLXg (SLXg), 12 canais e frequência de $5 \mathrm{~Hz}$; OmniStar TM 7000L (OTM), 8 canais e frequiência de $1 \mathrm{~Hz}$; GreenStar John Deere (JD), 10 canais e freqüência de 1 Hz; e Raven 115 (R115), 10 canais e freqüência de $10 \mathrm{~Hz}$ ). Também foram empregados receptores código C/A usados para navegação: Garmin Legend (L), Garmin Vista (V), Garmin Vista CX (CX), todos com 12 canais e $0,5 \mathrm{~Hz}$.

Para a coleta de dados dos receptores L1 código C/A computadores portáteis ou de mão foram utilizados com o programa SST Field Rover II, versão 7.13 (SST Development Group () e para os receptores código C/A, a própria memória interna para armazenamento dos dados. Utilizou-se intervalo de tempo de coleta de $15 \mathrm{~s}$ para todos os receptores.

Segundo Souza et al. (2005), a coleta de dados em dias consecutivos deve contemplar os mesmos efeitos e apresentar o mesmo padrão quando a geometria do levantamento permanece inalterada. Como o período orbital é de aproximadamente $12 \mathrm{~h}$ siderais, a posição dos satélites se repete, a cada dia, $4 \mathrm{~min}$ antes que a do dia anterior (Wolfgang \& Baumann, 2000), os tratamentos foram executados em dias consecutivos, adiantados de $4 \mathrm{~min}$ em cada dia, conforme apresentado na Tabela 1. 
Tabela 1. Descrição do arranjo dos tratamentos envolvidos no ensaio de caracterização de desempenho estático de receptores de GPS

\begin{tabular}{lcccc}
\hline \multirow{2}{*}{ Receptor } & $\begin{array}{c}\text { Correções } \\
\text { diferenciais }\end{array}$ & Data & Início & Fim \\
\cline { 4 - 5 } JD & SF1* & 15.04 .2008 & $19: 00$ & $15: 00$ \\
R115 & WAAS & 15.04 .2008 & $19: 00$ & $15: 00$ \\
JD & SF2* & 16.04 .2008 & $18: 56$ & $14: 56$ \\
R115 & EGNOS & 16.04 .2008 & $18: 56$ & $14: 56$ \\
OTM & SC* & 16.04 .2008 & $18: 56$ & $14: 56$ \\
CX & EGNOS & 16.04 .2008 & $18: 56$ & $14: 56$ \\
L & EGNOS & 16.04 .2008 & $18: 56$ & $14: 56$ \\
V & EGNOS & 16.04 .2008 & $18: 56$ & $14: 56$ \\
JD & SC & 17.04 .2008 & $18: 52$ & $14: 52$ \\
SLXg & SC & 17.04 .2008 & $18: 52$ & $14: 52$ \\
R 115 & SC & 17.04 .2008 & $18: 52$ & $14: 52$ \\
AG 132 & SC & 17.04 .2008 & $18: 52$ & $14: 52$ \\
CX & SC & 17.04 .2008 & $18: 52$ & $14: 52$ \\
L & SC & 17.04 .2008 & $18: 52$ & $14: 52$ \\
V & SC & 17.04 .2008 & $18: 52$ & $14: 52$ \\
AG 132 & SF & 18.04 .2008 & $18: 48$ & $14: 48$ \\
AG 132 & FEM* & 19.04 .2008 & $18: 44$ & $14: 44$ \\
\hline
\end{tabular}

* SF1 - correção diferencial StarFire 1; SF2 - correção diferencial StarFire 2; SC - sem correção diferencial; SF - Sem filtro; FEM - Filtro estático máximo

Quanto às configurações dos receptores, alguns possuem regulagem da intensidade de filtragem, outros possuem opções para sintonização de correções diferenciais pagas (SF1 e SF2) e livres (WAAS e EGNOS). Os satélites geoestacionários para sintonização das correções diferenciais públicas escolhidos para o ensaio, foram AOR-E (EGNOS) e Telesat (WAAS), devido às suas áreas de abrangência e resultados obtidos anteriormente (Machado et al., 2007). As configurações do receptor AG132 foram para a coleta de dados em forma estática com o filtro em intensidade normal de filtragem, filtro com intensidade máxima de filtragem e filtro desativado.

O receptor AG132, na configuração padrão, tem o filtro ativado no modo normal de intensidade, com o qual foi executado o ensaio do dia 17.04.2008 (Tabela 1). O receptor JD utilizou as correções diferenciais SF1 e SF2; os demais receptores utilizaram as correções diferencias EGNOS e WAAS, exceto os receptores OTM e SLXg e AG132.

A escolha do início de coleta foi definida por sorteio; antes do horário de início das coletas os receptores de GPS eram ligados com 30 min de antecedência para verificação de prováveis erros de armazenamento e configuração. O intervalo entre um tratamento e outro era de $4 \mathrm{~h}$ e durante esse intervalo os dados eram descarregados em um microcomputador utilizando o software Microsoft ActiveSync ${ }^{\circledR} 3.1$ e analisados para verificação de possíveis erros no salvamento dos arquivos ou perda de dados.

A avaliação do desempenho de receptores de GPS código C/A utilizando receptor GPS RTK como referência, em condição cinemática, foi realizada em percursos de um trator simulando a operação de plantio mecanizado de cana-de-açúcar para duas fileiras com espaçamento de $1,50 \mathrm{~m}$, resultando em passadas espaçadas $3,00 \mathrm{~m}$, a uma velocidade média de $1,94 \mathrm{~m} \mathrm{~s}^{-1} \mathrm{em}$ lavoura localizada no município de Barrinha, SP (coordenadas $21^{\circ} 12^{\prime} \mathrm{S}$ e $48^{\circ} 08^{\prime} \mathrm{W}$ ), pertencente à Usina São Martinho.

Coletaram-se dados entre os dias 23 e 24.04 .2007 e os equipamentos avaliados foram dois receptores GPS de navegação marca Garmin, modelos $\mathrm{V}$ e CX, que utilizam o código C/A com frequência de atualização de $0,50 \mathrm{~Hz}$. O trator estava equipado com piloto automático e a referência de percurso foi dada pelo receptor RTK L1/L2, marca Trimble ${ }^{\circledR}$, modelo AgGPS RTK, com frequência de atualização de dados de $5 \mathrm{~Hz}$, com correção a partir de uma estação base modelo 450 Trimble ${ }^{\circledast}$, configurada para fazer correções via rádio a cada segundo. A base estava localizada a $8 \mathrm{~km}$ da área selecionada. A coleta de dados foi realizada a cada $0,50 \mathrm{~m}$, ou $2 \mathrm{~s}$, priorizando sempre o menor intervalo. $\mathrm{O}$ datum configurado em todos os receptores foi o WGS-84.

O total de percursos paralelos foi de 13 passadas em cada dia, com comprimento individual de $1150 \mathrm{~m}$; no primeiro dia, com o início do ensaio às $12: 35 \mathrm{~h}$, a frequência de coleta dos receptores $\mathrm{V}$ e CX, foi de um ponto a cada $10 \mathrm{~s}$ e no segundo dia, de um ponto a cada $5 \mathrm{~s}$, tendo início às $9 \mathrm{~h}$ e $52 \mathrm{~min}$. Devido a problemas operacionais, não foi possível, nesse caso, seguir o critério de adiantamento de 4 min entre os dias de coleta de dados.

Obtiveram-se os erros perpendiculares aos trajetos do trator por meio de uma planilha eletrônica desenvolvida por Molin et al. (2011) e os cálculos de indicadores de acurácia foram obtidos da mesma forma que na etapa anterior.

\section{Resultados E DISCUSSÃO}

A variação média do "Position dilution of precision" (PDOP) e do número de satélites do dia 15.04.2008 a 20.04.2008 foi monitorada a partir da estação base GPS instalada no Centro de Informática do campus Luiz de Queiroz - CIAGRI, de coordenadas $22^{\circ} 42^{\prime} 37.8505^{\prime \prime S}$ e $47^{\circ} 38^{\prime} 06.2757^{\prime \prime} \mathrm{W}$ e está representada na Figura 2. Observa-se que não houve maiores variações, especialmente durante o dia.

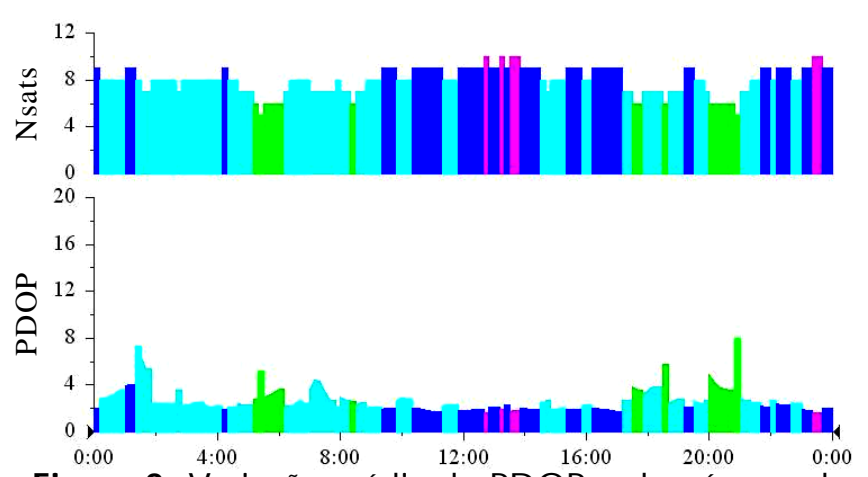

Figura 2. Variação média do PD O P e do número de satélites do dia 15.04.2008 a 20.04.2008 em Piracicaba, $\mathrm{SP}$

A dispersão de coordenadas de todos os receptores utilizados na primeira etapa, em condição estática, é representada na Figura 3. As coordenadas em UTM foram deduzidas de $229758 \mathrm{~m}$ no sentido L-O e 7485999 m no sentido N-S, para se obter coordenadas com valores numéricos menores; para se converter essas coordenadas para seus valores originais, basta somar essas constantes às coordenadas cartesianas do gráfico. A quantidade de pontos e diversidade de receptores não permite identificação 
detalhada, porém é possível observar a maior dispersão de alguns deles. Exemplos são as correções diferenciais EGNOS e WAAS que, ativadas no receptor R115, apresentaram uma dispersão maior de dados em relação ao receptor sem correção diferencial. O receptor OTM apresentou erros pontuais, sempre no mesmo local, da mesma forma que os receptores $\mathrm{V}$ e L sem correção diferencial; isto se deve à sua resolução limitada (número de casas decimais no campo segundos), dando a falsa impressão de serem dados com baixa variabilidade, em virtude do posicionamento aproximado e agrupado (Buick, 2002). O receptor JD, quando com a correção diferencial SF1 ou SF2, apresentou dados com alta concentração no marco de referência em comparação com os dados sem correção diferencial.

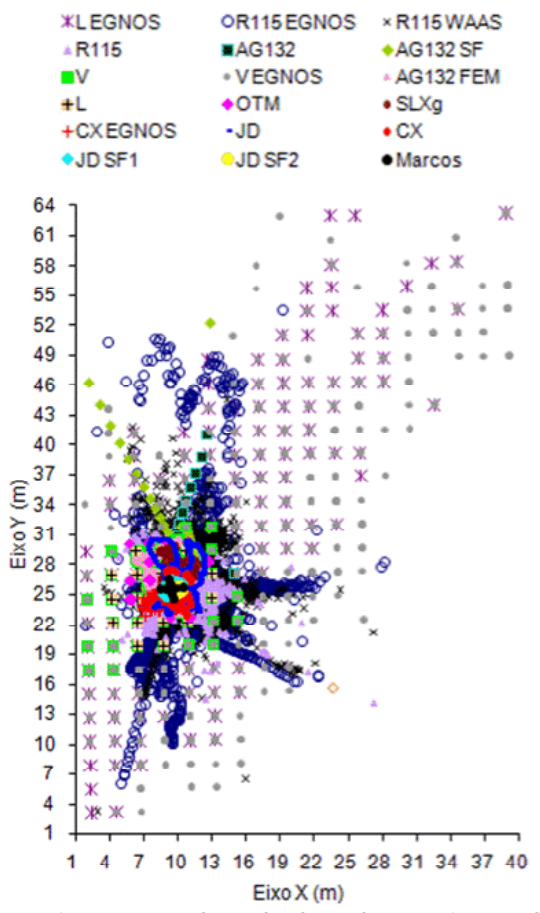

Figura 3. Dispersão dos dados de posição de todos os receptores avaliados em relação aos marcos de referência (nove, em cruz)
Apresentam-se, na Tabela 2, os indicadores de acurácia. Os valores RMS dos erros variaram de 0,15 a $10,76 \mathrm{~m}$ e $1 \mathrm{~s}$ variaram de 0,04 a 7,51 m, sendo que os maiores valores RMS e 1s foram observados com o receptor L com o sinal EGNOS ativado. Os menores erros, tanto relativos como absolutos, foram do receptor JD, com o sinal SF2. O receptor $\mathrm{CX}$, que utiliza código $\mathrm{C} / \mathrm{A}$, demonstrou desempenho surpreendente em relação aos receptores que utilizam portadora $\mathrm{L} 1$ com código $\mathrm{C} / \mathrm{A}$, resultando em erros menores que todos os receptores L1/CA sem uso de correções diferenciais.

Cappelli et al. (2006), que desenvolveram seu trabalho na região de Campinas, SP, encontraram acurácia, denominado erro absoluto (EA), variando de 1,80 a 3,70 m e desvio padrão de 1,08 a 2,11 m, usando receptores semelhantes aos usados nesta avaliação. No trabalho de Stombaugh et al. (2002), nos Estados Unidos, em avaliação estática de receptores de GPS, os valores de RMS variaram de 0,99 a 3,49 m.

Todos os receptores sintonizados com as correções diferenciais WAAS e EGNOS, exceto o receptor CX, apresentaram aumento nos valores de EP e RMS, que são indicativos de exatidão, se comparados com os mesmos receptores sem sinal de correção; já os indicadores de dispersão 1s, 2s e CEP de todos os receptores com as correções WAAS e EGNOS, apontaram aumento nos erros. Segundo Machado et al. (2007), avaliações estáticas de receptores GPS realizadas na região de Piracicaba, SP, mostram que a acurácia com a sintonização do sistema EGNOS foi inferior àquela sem correção diferencial e que os sinais diferenciais EGNOS e WAAS se mostraram pouco confiáveis e não recomendáveis para a região, devido à dificuldade de sintonia e recepção. De acordo com Sullivan et al. (2001), em avaliação de vários receptores de GPS usados em agricultura, alguns sintonizados com sinal WAAS, em um ensaio de longa duração, resultaram em valores RMS inferiores a 1,00 m. O trabalho foi conduzido nos Estados Unidos, em que o sistema WAAS efetivamente está disponível sendo que, embora seja sintonizado no Brasil, não atende à nossa região por não dispor de estações terrestres locais. O uso das correções diferencias SF1 e SF2 proporcionou

Tabela 2. Síntese dos indicadores de desempenho de todos os receptores avaliados em condição estática

\begin{tabular}{|c|c|c|c|c|c|c|c|c|c|c|}
\hline \multirow{2}{*}{ Receptor } & \multirow{2}{*}{ Correção diferencial } & \multicolumn{9}{|c|}{ Erros (m) } \\
\hline & & $* E P$ & RMS & $1 \sigma$ & $2 \sigma$ & E & $\mathbf{N}$ & $\sigma(E)$ & $\sigma(N)$ & CEP \\
\hline$L$ & Não & 2,11 & 2,49 & 1,02 & 2,04 & 1,11 & 1,52 & 1,07 & 0,89 & 2,26 \\
\hline $\mathrm{L}$ & EGNOS & 7,27 & 10,46 & 7,51 & 15,03 & 4,22 & 5,43 & 4,69 & 6,34 & 8,30 \\
\hline V & Não & 2,76 & 3,11 & 1,44 & 2,88 & 1,80 & 1,86 & 1,16 & 1,29 & 2,11 \\
\hline V & EGNOS & 6,90 & 10,04 & 7,29 & 14,59 & 3,71 & 5,21 & 4,83 & 6,05 & 9,37 \\
\hline$C X$ & Não & 0,85 & 1,02 & 0,56 & 1,13 & 0,41 & 0,62 & 0,31 & 0,62 & 0,80 \\
\hline$C X$ & EGNOS & 0,81 & 1,02 & 0,61 & 1,23 & 0,43 & 0,58 & 0,36 & 0,63 & 0,86 \\
\hline R115 & Não & 2,02 & 2,39 & 1,27 & 2,55 & 1,23 & 1,37 & 1,01 & 1,12 & 1,83 \\
\hline $\mathrm{R} 115$ & EGNOS & 3,66 & 5,15 & 3,62 & 7,24 & 1,78 & 2,70 & 1,73 & 3,62 & 4,59 \\
\hline R115 & WAAS & 2,85 & 3,56 & 2,12 & 4,42 & 1,53 & 2,04 & 1,42 & 2,03 & 2,96 \\
\hline OTM & Não & 1,62 & 1,92 & 1,03 & 2,06 & 0,83 & 1,10 & 0,91 & 0,97 & 1,62 \\
\hline AG132 & Não & 1,34 & 1,80 & 1,20 & 2,40 & 0,54 & 1,13 & 0,37 & 1,23 & 1,38 \\
\hline AG132-SF & Não & 1,15 & 1,77 & 1,34 & 2,68 & 0,73 & 0,73 & 0,67 & 1,28 & 1,66 \\
\hline AG132-FEM & Não & 1,24 & 1,70 & 1,16 & 2,32 & 0,66 & 0,90 & 0,62 & 1,13 & 1,50 \\
\hline SLXg & Não & 1,68 & 1,55 & 0,65 & 1,30 & 0,83 & 1,04 & 0,67 & 0,79 & 1,24 \\
\hline JD & Não & 1,83 & 2,19 & 1,20 & 2,40 & 0,80 & 1,46 & 0,67 & 1,26 & 1,64 \\
\hline JD & SF1 & 0,51 & 0,57 & 0,25 & 0,51 & 0,39 & 0,28 & 0,26 & 0,18 & 0,57 \\
\hline JD & SF2 & 0,14 & 0,15 & 0,04 & 0,08 & 0,07 & 0,10 & 0,06 & 0,04 & 0,08 \\
\hline
\end{tabular}

* EP - Erro de posição, 1s e 2s - desvio padrão, RMS - raiz quadrada média, E - erro na coordenada leste, N - erro na coordenada norte 
melhoria na acurácia em relação aos demais receptores; já o aumento na intensidade de filtragem do receptor AG132 - FEM resultou em diminuição dos valores de 1s, 2s e RMS. Os valores de EP e CEP mostraram não seguir tendência quanto ao aumento da intensidade de filtragem. Stombaugh et al. (2002), testando o uso de filtro em ensaio estático de receptor de GPS, encontraram valores de RMS de 0,99 m e sem filtro o RMS oscilou para $1,06 \mathrm{~m}$.

Os erros norte - sul foram maiores que leste - oeste na maioria dos receptores; somente o receptor JD, com correção SF1 apresentou erros no sentido leste - oeste maiores e o receptor AG132 - SF indicou erros de mesma magnitude nas duas direções. O desvio padrão foi maior na direção leste oeste somente nos receptores L sem correção e JD com SF1 e SF2. No restante dos receptores o desvio padrão na direção norte - sul foi maior que a direção leste - oeste e a explicação pode estar no fato de que há diferença entre "east dilution of precision" (EDOP) que é a diluição da precisão na direção E e o "north dilution of precision" (NDOP), que é a diluição da precisão da direção $\mathrm{N}$, principalmente em regiões de média latitude (Buick, 2002).

Os erros de altura entre todos os receptores variaram de 24,61 m a +26,10 m, com uma média de erro oscilando de 2,64 a $14,73 \mathrm{~m}$ entre os receptores (Tabela 3 ). O receptor JD, sem correção, resultou no maior erro $(14,73 \mathrm{~m})$ em relação à altitude de referência; já com as correções diferenciais SF1 e SF2, este mesmo receptor indicou as menores variações de altura. $\mathrm{O}$ maior desvio padrão $(9,85 \mathrm{~m}$ ) foi do receptor R115 com a ativação do sinal EGNOS, que também obteve o maior coeficiente de variação $(1,75 \%)$. O receptor SLXg resultou no menor erro, entre todos (2,64 m). Alguns dos receptores, em combinação com o coletor e o programa de coleta de dados, apresentaram variação nos intervalos de coleta, não seguindo rigorosamente aquele intervalo programado. Esta informação é apresentada de forma sintética na Tabela 4, mostrando a variação do desvio do intervalo de tempo de coleta de dados (ms), durante as $20 \mathrm{~h}$

Tabela 3. D esempenho dos receptores na determinação da altitude geométrica ou elipsoidal, nas avaliações estáticas

\begin{tabular}{|c|c|c|c|c|c|c|c|}
\hline \multirow{2}{*}{ Receptores } & \multirow{2}{*}{$\begin{array}{r}\text { Correção } \\
\text { diferencial }\end{array}$} & \multicolumn{3}{|c|}{ Erros } & $1 \sigma$ & $2 \sigma$ & \multirow{2}{*}{$\begin{array}{l}\text { CV } \\
(\%)\end{array}$} \\
\hline & & mínimo & médio & máximo & \multicolumn{2}{|c|}{ (m) } & \\
\hline L & Não & $-4,71$ & 3,64 & 7,10 & 4,90 & 9,80 & 0,87 \\
\hline $\mathrm{L}$ & EGNOS & 0,96 & 6,09 & 16,57 & 4,35 & 8,70 & 0,71 \\
\hline V & Não & $-6,96$ & 4,62 & 14,08 & 4,90 & 9,80 & 0,87 \\
\hline V & EGNOS & $-3,71$ & 6,55 & 12,37 & 4,02 & 8,04 & 0,71 \\
\hline$C X$ & Não & $-4,60$ & 4,11 & 9,78 & 3,39 & 6,78 & 0,60 \\
\hline$C X$ & EGNOS & 1,46 & 5,07 & 10,30 & 2,19 & 4,38 & 0,38 \\
\hline R115 & Não & $-1,51$ & 4,30 & 14,71 & 4,93 & 9,86 & 0,87 \\
\hline R115 & EGNOS & $-24,61$ & 5,65 & 15,02 & 9,85 & 19,70 & 1,75 \\
\hline R115 & WAAS & $-16,28$ & 5,76 & 13,81 & 6,75 & 13,50 & 1,19 \\
\hline OTM & Não & 1,43 & 4,68 & 9,03 & 2,20 & 4,40 & 0,39 \\
\hline AG 132 & Não & 1,69 & 4,11 & 6,15 & 2,60 & 5,20 & 1,47 \\
\hline AG132-FEM & Não & $-2,18$ & 3,94 & 8,83 & 2,55 & 5,10 & 0,45 \\
\hline AG 132-SF & Não & $-1,39$ & 4,74 & 9,27 & 2,84 & 5,68 & 0,50 \\
\hline SLXg & Não & $-2,19$ & 2,64 & 6,33 & 2,20 & 4,40 & 0,39 \\
\hline JD & Não & 9,00 & 14,73 & 26,10 & 4,46 & 8,92 & 0,77 \\
\hline JD & SF1 & 2,24 & 3,48 & 4,69 & 0,75 & 1,50 & 0,13 \\
\hline JD & SF2 & 3,36 & 3,67 & 3,90 & 0,16 & 0,32 & 0,02 \\
\hline
\end{tabular}

de ensaio para todos os receptores avaliados; este fato adiciona uma variável quando se deseja avaliar o desempenho desses receptores, não sendo possível, para alguns deles, a fixação exata do intervalo de coleta. Todos os receptores foram configurados para taxa de coleta a cada $15 \mathrm{~s}$ mas nos arquivos se encontraram erros de atraso variando de 857 a $1999 \mathrm{~ms}$, com média de $1311 \mathrm{~m}$, em cada intervalo de $15 \mathrm{~s}$ da taxa de coleta, com média de hora em hora.

Tabela 4. D escrição dos erros de tempo entre os intervalos de coleta dos receptores G PS avaliados estaticamente

\begin{tabular}{|c|c|c|c|c|c|c|}
\hline \multirow{2}{*}{ Receptor } & \multirow{2}{*}{$\begin{array}{l}\text { Correção } \\
\text { diferencial }\end{array}$} & \multicolumn{3}{|c|}{ Erros (ms) } & \multirow{2}{*}{$\begin{array}{c}\sigma \\
\text { (ms) }\end{array}$} & \multirow{2}{*}{$\begin{array}{l}\text { CV } \\
(\%)\end{array}$} \\
\hline & & Mínimo & Médio & Máximo & & \\
\hline R 115 & Não & 710 & 900 & 2250 & 326,00 & 36,00 \\
\hline R 115 & EGNOS & 679 & 887 & 3549 & 629,00 & 71,00 \\
\hline R 115 & WAAS & 655 & 1132 & 3565 & 721,00 & 64,00 \\
\hline OTM & Não & 884 & 918 & 947 & 16,92 & 1,84 \\
\hline AG 132 & Não & 1990 & 1999 & 2000 & 2,62 & 0,13 \\
\hline AG 132-SF & Não & 1990 & 1998 & 2000 & 3,16 & 0,16 \\
\hline AG 132-FEM & Não & 1971 & 1991 & 2000 & 10,42 & 0,52 \\
\hline JD & Não & 978 & 995 & 1000 & 5,89 & 0,59 \\
\hline JD & SF1 & 978 & 990 & 1000 & 9,01 & 0,90 \\
\hline JD & SF2 & 973 & 992 & 1000 & 7,67 & 0,77 \\
\hline SLXg & Não & 959 & 977 & 1000 & 12,42 & 1,27 \\
\hline
\end{tabular}

O receptor que teve o maior erro médio foi o AG132, com 1999 ms e o menor erro foi do receptor R115 sem correção diferencial, com $857 \mathrm{~ms}$. O receptor R manteve o erro estável a maior parte do tempo mas com picos de erro chegando a 3565 ms. Com a ativação das correções WAAS e EGNOS o receptor $\mathrm{R}$ aumentou este descompasso em relação ao mesmo receptor sem correção diferencial. As correções SF1 e SF2 resultaram no menor erro de intervalo de tempo de coleta em relação ao receptor sem correção diferencial.

Os receptores da marca Garmin utilizam um sistema de arquivamento dos dados, diferente dos demais. Eles guardam os arquivos em uma memória interna, não apresentando erros de tempo de intervalo de coleta. Os receptores L1, código C/A, não possuem memória interna, necessitando de coletor de dados.

Esses erros de atraso na coleta de dados podem ocorrer devido ao programa que atua no computador de mão e que, quando registra os dados pelo tempo programado, coleta a sentença do arquivo NMEA quando ela não está no início, tendo que esperar a atualização da sentença seguinte para fazer arquivamento dos dados, evento que pode ser notado pelo fato do receptor $\mathrm{R}$ trabalhar em frequência de atualização mais elevada $(10 \mathrm{~Hz})$ e apresentar o menor erro entre os intervalos de coleta quando comparado com o restante dos receptores que trabalham com frequência de $1 \mathrm{~Hz}$; portanto, em receptores que trabalham com frequências mais elevadas, $o$ programa de coleta de dados tem que esperar menos pelo início da nova sentença.

Com relação à segunda etapa do trabalho, em testes preliminares ligando os receptores de GPS diretamente em um computador com o software Microsoft Windows Hyper Terminal $^{\circledR}$, verificou-se que os tempos das sentenças de atualizações de dados tinham erros inconstantes e que a 
frequência de atualização dos receptores era de $0,5 \mathrm{~Hz}$, enquanto o receptor RTK trabalhava em $5 \mathrm{~Hz}$; assim, não foi possível o sincronismo do tempo para o cálculo em duas dimensões, leste e norte; portanto, os erros obtidos foram apenas de paralelismo. Durante a realização dos ensaios o HDOP variou de 0,80 a 1,00 no dia 23.04 mas no dia 24.04.2007 se manteve constante em 1,00; referidos dados foram fornecidos pelo receptor RTK.

A Tabela 5 apresenta os resultados dos indicadores de desempenho dos receptores de GPS avaliados (EM, RMS, $1 \sigma$, 2). Com o aumento na frequência de coleta de dados houve diminuição no EMP e RMS, que são indicadores de exatidão, e 1,2 , que indicam a dispersão dos dados. O receptor CX obteve os menores erros nas duas frequências ensaiadas, em relação ao receptor V. Ehsani et al. (2003), nos Estados Unidos e utilizando um receptor RTK como referência, testaram vários modelos de receptores da mesma marca daqueles aqui utilizados e outros da mesma categoria, em cima da cabine de uma caminhonete, encontrando RMS variando de 0,70 a 1,30 m e de 0,10 a $0,15 \mathrm{~m}$; em uma plataforma circular de ensaio Stombaugh et al. (2002), também nos Estados Unidos, encontraram, trabalhando com receptores da mesma categoria, RMS variando de 0,72 a 3,31 m e Stombaugh et al. (2005), em uma pista de ensaio, avaliaram um receptor semelhante tendo o RMS variando 0,85 a 3,00 $\mathrm{m}$ nos percursos retos da pista de ensaio.

Tabela 5. Indicadores de desempenho dos receptores de GPS código C/A avaliados utilizando receptor RTK como referência em condição cinemática

\begin{tabular}{lccccc}
\hline \multirow{2}{*}{ Receptor } & $\begin{array}{c}\text { Intervalo } \\
\text { de coleta }\end{array}$ & \multicolumn{5}{c}{ Erros } \\
\cline { 3 - 6 } & (s) & *EMP & \multicolumn{5}{c}{ RMS } & $1 \sigma$ & $\mathbf{5} \sigma$ \\
\cline { 3 - 6 } & 10 & 2,98 & 1,58 & 0,73 & 1,46 \\
V & 10 & 2,80 & 1,47 & 0,34 & 0,68 \\
CX & 05 & 1,70 & 0,96 & 0,73 & 1,46 \\
$V$ & 05 & 1,57 & 0,84 & 0,30 & 0,60 \\
CX & 05 &
\end{tabular}

* EMP - Erro médio de paralelismo, RMS raiz quadrada média, 1 e $2 \mathrm{~s}$ - desvio padrão

Os receptores de navegação avaliados cinematicamente, mostraram que podem ser usados para determinadas aplicações agrícolas, como monitoramento de produtividade, cálculo de área para fins gerenciais e outras atividades que requerem acurácia de 1,00 a 3,00 m (Buick, 2002). Não são indicados, porém, para orientação de veículos agrícolas (barra de luz) que requerem acurácia da ordem de $0,30 \mathrm{~m}$, bem como controle de tráfego, que necessita de acurácia da ordem de 0,02 a 0,04 m.

A metodologia utilizando RTK como referência mostrou-se de fácil manuseio e de rápida manipulação e processamento dos dados, mas não permite calcular os erros na direção do deslocamento. Para futuros trabalhos deve-se trabalhar de alguma forma para sincronizar os tempos dos receptores a serem ensaiados com o receptor de GPS RTK e fazer ensaios com diversas frequências de coleta, tendo como variáveis a distância e o tempo.

\section{CONCLUSÕES}

1. As correções diferenciais EGNOS e WAAS na região de Piracicaba, SP, não melhoram a acurácia do posicionamento, causando, por vezes, a sua degradação. A utilização das correções diferenciais privadas via satélite proporcionou diminuição nos erros de posicionamento.

2. O uso de receptores de GPS para determinação de altitude deve ser ponderado, tal como a finalidade e a resolução necessárias para determinadas atividades.

3. O aumento na frequência de coleta de dados nos receptores de GPS código C/A e utilizando receptor RTK como referência, em condição cinemática, resultou em diminuição dos erros de posicionamento.

4. O ensaio sob condição cinemática, com GPS RTK de referência, permitiu o cálculo de erros no sentido perpendicular ao percurso, indicando ser de fácil execução.

\section{LITERATURA CITADA}

Bergtold, J. S.; Raper, R. L.; Schwab, E. B. The economic benefit of improving the proximity of tillage and planting operations in cotton production with automatic steering. Applied Engineering in Agriculture, v.25, p.133-143. 2009.

Buick, R. GPS guidance-making an informed decision. In: Conference on Precision Agriculture, 3., 2002, Madison. Abstracts... St Joseph: ASA/CSSA/SSSA, 2002. p.19792004.

Cappelli, N. L.; Umezu, C. K.; Silveira, A. C.; Garcia, A. P. Desempenho comparativo entre receptores GPS. Revista Brasileira de Agroinformática, v.8, n.1 , p.63-77, 2006.

Chosa, T.; Omine, M.; Itani, K. Dynamic performance of global positioning system velocity sensor for extremely accurate positioning. Biosystems Engineering, London, v.97, n.1, p.39, 2007.

Devlin, G. J.; McDonnell, K. P.; Ward, S. M. Performance accuracy of low-cost dynamic non-differential GPS on articulated trucks. Applied Engineering in Agriculture, v.23, p.273-279. 2007.

Ehsani, M. R.; Sullivan, M. D.; Zimmerman, T. L.; Stombaugh, T. Evaluating the dynamix accuracy of low cost GPS receivers. St. Joseph: ASABE, 2003. Meeting Paper $\mathrm{N}^{\circ} 031014$

Machado, T. M.; Povh, F. P.; Molin, J. P. Acurácia e avaliação do funcionamento das correções diferenciais waas e egnos na região de Piracicaba, SP. In: Congresso Brasileiro de Engenharia Agrícola, 35, 2007, Bonito. Anais... Jaboticabal: SBEA, 2007. CD-Rom

Min, M.; Ehsani, R.; Salyani, M. Dynamic accuracy of GPS receivers in citrus orchards. Applied Engineering in Agriculture, v.24, p.861-868. 2008.

Molin, J. P; Carreira, P. T. Metodologia para ensaios cinemáticos de receptores de GNSS utilizando um GPS RTK como referência. Revista Brasileira de Agroinformática, v.8, p.5362, 2006.

Molin, J. P.; Povh, F. P.; Paula, V. R.; Salvi, J. V. Método de avaliação de equipamentos para direcionamento de veículos agrícolas e efeito de sinais de GNSS. Engenharia Agrícola, v.31, p.121-129, 2011.

Molin, J. P; Souza, A. B. M.; Fontana, G.; Nagumo, G. K. Análise comparativa de sensores de velocidade de deslocamento em função da superfície. Engenharia Agrícola, v.25, p.768$773,2005$. 
Motomiya, A. V. A.; Molin, J. P., Chiavegato, E. J. Utilização de sensor óptico ativo para detectar deficiência foliar de nitrogênio em algodoeiro. Revista Brasileira de Engenharia Agrícola e Ambiental. , v.13, p.137-145, 2009.

Nørremark, M.; Griepentrog, H. W.; Nielsen, J.; Søgaard, H. T. The development and assessment of the accuracy of an autonomous GPS-based system for intra-row mechanical weed control in row crops. Biosystems Engineering, v.101, p.396-410. 2008.

Silva, C. B.; Moraes, M. A. F. D.; Molin, J. P. Adoption and use of precision agriculture technologies in the sugarcane industry of São Paulo state, Brazil. Precision Agriculture, v.12, p.67-81, 2011.

Smith, L. A.; Thomson, S. J. GPS position latency determination and ground speed calibration for the SATLOC Airstar M3. Applied Engineering in Agriculture, v.21, p.769-776. 2005.
Souza, E. M.; Polezel, W. G. C.; Monico, J. F. G. Avaliação do nível de multicaminho no posicionamento relativo GPS e sua atenuação através da análise de multiresolução. Boletim de Ciências Geodésicas, v.11, p.221-234. 2005.

Stombaugh, T.; Cole, J.; Shearer, S.; Koostra, B. A Test facility for evaluating dynamic GPS accuracy. In: European Conference on Precision Agriculture, 6, 2005, Berlin. Abstracts... St. Joseph: Wageningen Academic Publishers, 2005. p.605-612.

Stombaugh, T.; Shearer, S.; Fulton, J. Standards for comparison of GPS receiver performance. In: Conference on Precision Agriculture, 3, 2002, Madison. Abstract... St. Joseph: ASA/ CSSA/SSSA, 2002. p.1049-1059.

Sullivan, M.; Ehsani, M. R.; Walker, J. T.; Levison, P.; Lang, L. Accuracy and availability of WAAS for precision agriculture. St. Joseph: ASABE, 2001. Meeting Paper $N^{\circ}$ 01-1155

Wolfgang, L.; Baumann, S. Global navigation satellite systems. Computers and Electronics in Agriculture, v.25, p.67-85. 2000. 